\title{
Bovine mammary epithelial cell cultures for the study of mammary gland functions
}

\author{
Magdalena Jedrzejczak • Iwona Szatkowska
}

Received: 2 June 2013 / Accepted: 24 October 2013 / Published online: 14 November 2013 / Editor: T. Okamoto

(C) The Author(s) 2013. This article is published with open access at Springerlink.com

\begin{abstract}
In the present study, the analysis of epithelial cells derived from various sources was undertaken, beginning from the mammary gland tissue through the primary cultures and their subsequent passages. The objective of the study was the comparative analysis of the stage in which the epithelial cells obtained from individuals in different lactation cycles and disparate phases of cell culture growth are the most suitable for morphological research and analysis of gene expression activity. The cultures of primary bovine mammary epithelial cells and passages were identified morphologically using immunocytochemical methods. After positive identification, realtime PCRs were performed for the analysis of the expression level of casein genes, whey protein genes, and butyrophilin gene. The most stable reference genes in real-time PCRs for the mammary gland tissue and cell cultures were also determined. Of the reference genes, the $U X T$ and GAPDH genes appeared to be the most stable ones for the mammary gland tissue samples and epithelial cell cultures. The results obtained allowed concluding that the mammary gland samples collected from heifers constituted the most effective material for the initiation of primary cultures. The primary cultures formed characteristic for the mammary gland tissue dome structures, which images were obtained using confocal microscopy. The highest levels of expression of the CSN1S1, CSN1S2, CSN2, and $C S N 3$ genes were detected in primary cultures. The levels of expression of whey protein genes ( $L A L B A$ and $B G L)$ were highest in the second passage. The most abundant expression of the BTN1A1 gene was observed in primary cultures and the third passage. On the basis of the whole experiment, it can be
\end{abstract}

\footnotetext{
M. Jedrzejczak $(\bowtie) \cdot$ I. Szatkowska

Laboratory of Molecular Cytogenetics, West Pomeranian University

of Technology, Doktora Judyma 10, Szczecin 71-460, Poland

e-mail: mjedrzejczak@zut.edu.pl

I. Szatkowska

e-mail: iwona.szatkowska@zut.edu.pl
}

concluded that primary cultures and cells of the second passage derived from heifer individuals appeared to be the best materials for the analysis of mammary gland function and gene expression activity.

Keywords Bovine epithelial cell culture · Mammary gland · Gene expression · Casein genes - Whey proteins genes · Butyrophilin gene

\section{Introduction}

Mammary structure, function, and development have been extensively studied for over four decades. Along with the development of analytical tools and new research techniques (transcriptomics, proteomics, metabolomics analyses), the molecular mechanisms of lactation, involution, lactogenesis, and lactopoesis can be more accurately analyzed (Loor and Cohick 2009). The expression of milk protein genes in epithelial cells depends on various factors. Gaining knowledge about them is relevant because the studies that focus on mammary gland physiology have important implications for the agricultural sector and food industry. Investigation of bovine mammary gland biology is significant not only for milk production but also for carcinogenesis studies (Povey and Osborne 1969; Kozłowski and Motyl 2007). Another stream of research is to provide theoretical and methodical foundations for studies on the mammary gland as a transgenic universal bioreactor. Apart from a purely practical dimension, the possibility of observation and analysis of cellular and subcellular processes allows capturing a complex network of physiological relations and answering the questions posed by the biological sciences. The role of studies on mammary glands is to gain knowledge of cell biology, reproductive biology, and histology (Kozłowski and Motyl 2007; Jedrzejczak 2010b; Jedrzejczak 2010a). When undertaking 
in vitro experiments on mammary gland function, the key role is played by the appropriate choice of the research model. A popular approach is the selection of established cell lines as a convenient research material. However, considerable number of such lines does not solve the problem of comparability and scope of the conducted research. In addition, cells maintained in in vitro systems for prolonged time periods lose their natural properties (Buhering et al. 2004). In this study, analysis of tissue material from the mammary gland, primary cultures, and subsequent passages was carried out. The aim of the present study was the comparative analysis of the epithelial cells obtained from individuals in different lactation cycles for morphological and gene expression analysis. The results obtained can be useful in many studies related to the structure and function of bovine mammary gland.

\section{Materials and Methods}

Cell isolation and primary cell culture. Primary cell cultures were established from mammary parenchymal tissue. Small pieces of the mammary tissue of Polish Holstein-Friesian cows were aseptically removed from the udder immediately following slaughter from individuals in various stages of their life (heifers, mid-lactation, involution). Tissue pieces were collected in 50-ml conical centrifuge tubes (BD Bioscience, San Jose, CA) with $1 \times$ DPBS (Gibco, Langley, OK), transported, and preserved at $4^{\circ} \mathrm{C}$ until cell isolation and modified primary cell culture (method as described by Huynh et al. 1991) was started. The mammary tissue pieces were washed twice with $1 \times$ DPBS (Gibco) before digestion. The tissue samples were minced using surgical scissors. Minced samples were incubated in aseptic Hank's balanced salt solution (Gibco) for $1.5 \mathrm{~h}$ at $37^{\circ} \mathrm{C}$. The prepared tissue was digested with trypsin-EDTA solution (Sigma-Aldrich, St. Louis, $\mathrm{MO}$ ) for $1 \mathrm{~h}$ at $37^{\circ} \mathrm{C}$. The digest was filtered through a nylon mesh (BD Bioscience, $100 \mu \mathrm{m}$ ) and the filtrate centrifuged for $10 \mathrm{~min} / 1,250 \mathrm{rpm}$ (Eppendorf $5804 \mathrm{R}$, Eppendorf, Hamburg, Germany). The cell inoculum was plated in Dulbecco's modified Eagle's medium (DMEM) supplemented with $20 \% \mathrm{FBS}$, insulin $(1 \mu \mathrm{g} / \mathrm{ml})$, amphoterycin B $(2.5 \mu \mathrm{g} /$ $\mathrm{ml})$, and penicillin-streptomycin $(50 \mathrm{IU} / \mathrm{ml})$ on non-coated polystyrene Petri dishes with the surface modified for enhanced cell culture (BD Primaria ${ }^{\mathrm{TM}}, 35 \mathrm{~mm}$, BD Bioscience). Then, the cells were incubated in the incubator (Memmert $\mathrm{GmbH}+\mathrm{Co} . \mathrm{KG}$, Schwabach, Germany) at $37^{\circ} \mathrm{C}$, $5 \% \mathrm{CO}_{2}, 95 \%$ humidity for $2 \mathrm{~h}$ (pre-plating). After $2 \mathrm{~h}$, DMEM was changed and in the fresh DMEM cells were maintained at $37^{\circ} \mathrm{C}$ in a humidified atmosphere of $5 \% \mathrm{CO}_{2}$. The medium was changed every $2 \mathrm{~d}$. The primary cell cultures were trypsinized at $\sim 80 \%$ confluency (trypsin-EDTA $0.25 \%$ solution, Sigma-Aldrich) and passaged. The primary cell cultures were passaged on the tenth day of culture. Cells in the first passage were trypsinized on the seventh day of the culture. On the fourth day of culture, epithelial cells of the second and third passages were harvested. Cell cultures were visualized with a Nikon TS-100 microscope (NIS Elements F Package, camera Nikon DS-Fi1, Nikon, Melville, NY).

Single-cell cloning by serial dilution. When the primary cell culture was established, the initial material was not homogenous. To solve this problem, the first passage was prepared by means of single-cell cloning by serial dilution, as described by Ryan (2005), in 96-well plates (Cell+, Sarstedt, Nümbrecht, Germany). The first passage was maintained at $37^{\circ} \mathrm{C}, 95 \%$ humidity, and $5 \% \mathrm{CO}_{2}$. The cells in the first passage were trypsinized at $\sim 80 \%$ confluency and transferred into 24 -well plates (Cell+, Sarstedt). The cells of the second and third passages were used for further studies as experimental materials of high homogeneity.

Testing for Mycoplasma in cell cultures. For Mycoplasma testing, cells were fixed and DAPI staining solution was used (Sigma-Aldrich). Microscope slides were prepared using Gel Mount ${ }^{\mathrm{TM}}$ Aqueous Mounting Medium (Sigma-Aldrich). The slides were analyzed using a confocal laser microscope (Nikon Eclipse TE 2000-S). Molecular Mycoplasma tests through molecular analysis were performed with genomic DNA extraction from the culture media according to the method described by Wirth et al. (1994). For Mycoplasma species identification in the culture media, PCRs were prepared. The following species-specific primers (fragments of sequence of the Mycoplasma 16S rRNA gene) were used in PCR reaction to identify Mycoplasma species (e.g., Mycoplasma hyorhinis, Mycoplasma orale, Mycoplasma fermentas, Mycoplasma pirum) and species specific for Bovidae-Mycoplasma arginini and Acholeplasma laidlawii: F-5'-GGGAGCAA ACAGGATTAGATACCCT-3' (GPO3) and $R-5^{\prime}$-TGCACC ATCTGTCACTCTGTTAACCTC-3' (MGSO; Kuppeveld et al. 1994; Kong et al. 2001). PCR amplicons were analyzed using horizontal electrophoresis through 2\% agarose gel (Prona Agarose). Genomic DNA of Mycoplasma bovis was used as a positive control.

Morphological cell identification. Cells from the primary cell cultures, i.e., the first, second, and third passages, were fixed for morphological and subcellular identification. Cells were fixed with $4 \%$ paraformaldehyde solution for $10 \mathrm{~min}$ and perforated with $70 \%$ methanol solution for $1 \mathrm{~h}$ (SigmaAldrich). For basic morphology analysis, the cell cultures were stained in $20 \%$ Giemsa solution for $8 \mathrm{~min}$ and propidium iodine solution $(0.6 \mu \mathrm{g} / \mathrm{ml})$ for $5 \mathrm{~min}$ (Sigma-Aldrich). For standard morphological study, epithelial cells were prepared on the tenth day of culture. On the 14th day of cell culture, living and fixed cells were taken only for dome structure analysis. 
Immunocytochemistry. The presence of cytokeratin (Moll et al. 1982) in cultured cells was investigated using monoclonal antibodies. First, the cells were incubated with the primary monoclonal antibody (1:300 in DPBS) for $1 \mathrm{~h}$ (Monoclonal Anty-Pan Cytokeratin, Sigma-Aldrich). In the second step, two visualization systems were used. The first method used DakoCytomation EnVison+ System-HRP (30-min incubation with $2 \%$ solution; Dako, Glostrup, Denmark), and subsequently the slides were visualized with Nikon NIS Elements Basic Research package (Nikon Eclipse E-200). The second method used fluorescein isothiocyanate (FITC)-labeled antimouse IgG antibody (1:30 in DPBS) for 30 min (Anti-mouse IGG, Fab specific, Sigma-Aldrich) with DAPI solution (10 $\mu \mathrm{m} / \mathrm{ml}$ for $10 \mathrm{~min}$ for cell nuclei localization; SigmaAldrich) and the slides imaged with a confocal laser microscope (Nikon Eclipse TE 2000-S).

$R N A$ isolation and reverse transcription reaction. For gene expression analysis, total RNA was isolated from mammary gland tissues and cell cultures. The small tissue fragments were placed in RNAlater ${ }^{\circledR}$ (Sigma-Aldrich) and preserved at $4^{\circ} \mathrm{C}$ until total RNA isolation. Cell cultures for total RNA isolation were washed with $1 \times$ DPBS (Gibco) and removed from the culture surface using tissue cell scrapers (TPP $\left.{ }^{\circledR}\right)$. The total RNA from primary cell cultures were obtained on the tenth day of cell culture (before cells reach confluence). Also, from subsequent passages, total RNA samples were isolated before the cell culture reaches a plateau phase (on the seventh day of culture for the first passage and on the fouth day of culture for cells in the second and third passages). The RNA samples were isolated using Total RNA (A\&A Biotechnology, Gdynia, Poland) according to the method of Chomczynski and Sacchi (1987). RNA quality was analyzed using horizontal electrophoresis through $1.5 \%$ agarose gel (Prona Agarose, EU). For RNA quantity determination, the samples were measured using Quant-i $\mathrm{T}^{\mathrm{TM}}$ RNA BR Assay Kit and Qubit fluorometer (Invitrogen GmbH, Darmstadt, Germany). Contaminating genomic DNA was removed from the RNA samples by DNase I digestion (Fermentas UAB, Vilnius, Lithuania). Total RNA $(1 \mu \mathrm{g})$ was reverse-transcribed using the RevertAid ${ }^{\mathrm{TM}}$ Premium First Strand cDNA Synthesis Kit (Fermentas UAB). Each sample was reverse-transcribed in triplicate. Single-stranded cDNA samples were preserved at $20^{\circ} \mathrm{C}$ until real-time PCR reactions were performed. Before real-time PCRs, cDNA samples were quantified using Quant-iT ${ }^{\mathrm{TM}}$ ssDNA Assay Kit and Qubit fluorormeter (Invitrogen).

Real-time PCR. Single-strand cDNA (40 ng) was used for real-time PCRs; all samples were run in triplicate in the total volume of $15 \mu \mathrm{l}$ containing $12.5 \mu \mathrm{l}$ of SybrGreen PCR Master Mix (KAPA ${ }^{\mathrm{TM}}$ SYBR ${ }^{\circledR}$ qPCR Kit, KapaBiosystems, Woburn,
MA), $200 \mathrm{nM}$ of each primer, and $\mathrm{H}_{2} \mathrm{O}$ up to $15 \mu \mathrm{l}$. Real-time PCRs were performed on Rotor-Gene (Qiagen $\mathrm{GmbH}$, Hilden, Germany). Reference genes and genes of interest were analyzed using the primers listed in Table 1. The group of reference genes comprised $\beta$-actin gene $(A C T B)$, glyceraldehyde-3-phosphate dehydrogenase gene $(G A P D H)$, small subunit (18S) ribosomal RNA gene (18SrRNA), the large subunit (28S) ribosomal RNA gene (28S rRNA), and UXT (Table 1). Subsequently, most stable reference genes were selected using geNorm application. Stability (M-gene stability measure) was analyzed. The normalization factors $\mathrm{NF}_{n}$ and $\mathrm{NF}_{n+1}$ were calculated (Vandesompele et al. 2002). In the group of genes of interest, casein genes, whey protein genes, and butyrophilin gene were chosen. All primer sequences were designed using Primer3 Input software (version 0.4.0, http://frodo.wi.mit.edu/primer3/; Table 1) and were synthesized by the DNA Sequencing and Oligonucleotyde Synthesis Lab in the Institute of Biochemistry and Biophysics PAN (www.ibb.waw.pl). Relative transcript quantification standard curves were plotted using a sixfold serial dilution of cDNA. The reaction efficiency for all reference and experimental genes of interest ranged between 0.95 and 1.03. The relative level of expression for genes of interest was analyzed using the delta- $C_{\mathrm{t}}$ method and was normalized by dividing by a proper normalization factor (Vandesompele et al. 2002).

Statistical analyses. Analyses were performed using the STATISTICA 8.0 (StatSoft Inc., Tulsa, OK) statistical software. The Kruskal-Wallis analysis of variance by ranks was used for data obtained from tissue fragment examinations. For data evaluated from epithelial cell cultures, the Friedman ANOVA non-parametric test was applied.

\section{Results}

Analysis of tissue material for establishing mammary gland cell culture. Parenchymal tissue of the mammary gland was taken from heifers, lactating dairy cows, and individuals in involution. Establishment of primary mammary epithelial cell cultures varied for samples of tissue taken from individuals in different stages of mammary gland metabolism activity. The age of cows and individual predispositions also had an influence on the growth of cells in primary cultures and passages, even though an identical cell culture environment was maintained. Fragments of mammary gland tissue obtained from heifers constituted the most efficient material for establishing primary cell cultures and for the analysis of passages from the first to the third. Maintaining the mammary cell cultures from tissue fragments obtained from individuals in involution was more efficient than those from lactating individuals, but less efficient than for cells obtained from heifers. 
Table 1 Primer sequences and amplicon size for real-time PCR analysis

\begin{tabular}{|c|c|c|c|}
\hline Gene & Primer sequence $\left(5^{\prime} \rightarrow 3^{\prime}\right)$ & Amplicon size & Reference \\
\hline$A C T B$ & $\begin{array}{l}\text { F-GTCCACCTTCCAGCAGATGT } \\
\text { R-AAAGCCATGCCAATCTCATC }\end{array}$ & 163 & NM_173979 \\
\hline$G A P D H$ & $\begin{array}{l}\text { F-TGACCCCTTCATTGACCTTC } \\
\text { R-TACTCAGCACCAGCATCACC }\end{array}$ & 180 & NM_001034034 \\
\hline $18 S r R N A$ & $\begin{array}{l}\text { F-AAACGGCTACCACATCCAAG } \\
\text { R-CCTCCAATGGATCCTCGTTA }\end{array}$ & 155 & DQ222453 \\
\hline $28 S r R N A$ & $\begin{array}{l}\text { F-GGCCACTTTTGGTAAGCAGA } \\
\text { R-GATTCGGCAGGTGAGTTGTT }\end{array}$ & 178 & AY639443 \\
\hline$U X T$ & $\begin{array}{l}\text { F-TGGACCATCGTGACAAGGTA } \\
\text { R-TGAAGTGTCTGGGACCACTG }\end{array}$ & 155 & NC_007331 \\
\hline CSN1S1 & $\begin{array}{l}\text { F-CAAAGTACCCCAGCTGGAAA } \\
\text { R-ACCAGGCACCAGATGGATAG }\end{array}$ & 182 & NM_181029 \\
\hline CSN1S2 & $\begin{array}{l}\text { F-CGAGGACAAAGCAAACATGA } \\
\text { R-AGGTTCTCCTTGCTGGGATT }\end{array}$ & 165 & NM_174528 \\
\hline CSN3 & $\begin{array}{l}\text { F-ATACTGTGCCTGCCAAGTCC } \\
\text { R-CTTGTAGGCTCGCCACTAGC }\end{array}$ & 154 & NM_174294 \\
\hline CSN2 & $\begin{array}{l}\text { F-CAGAAAGCAGTGCCCTATCC } \\
\text { R-GCCATATTTCCAAGTCGCAGT }\end{array}$ & 169 & NM_181008 \\
\hline BTN1A1 & $\begin{array}{l}\text { F-AGGCAGGACGAAAACTACGA } \\
\text { R-CCTGTGAGTTCGCCACTGTA }\end{array}$ & 165 & NM_174508 \\
\hline$B G L$ & $\begin{array}{l}\text { F-AAGTCCTTGTGCTGGACACC } \\
\text { R-TTGAGGGCTTTGTCGAATTT }\end{array}$ & 158 & NM_173929 \\
\hline$L A L B A$ & $\begin{array}{l}\text { F-TACTGGTTGGCCCATAAAGC } \\
\text { R-CAAGGGGGTACAAAGAAGCA }\end{array}$ & 158 & NM_174378 \\
\hline
\end{tabular}

Establishment of bovine mammary epithelial cell cultures. The obtained primary cell cultures were a heterogeneous population of epithelial, fibroblast-like, and adipocyte cells. When grown on a non-coated plastic surface, epithelial cells had a typical cobblestone shape (Fig. 1a) and formed alveoli-like structures when the cells were cultured for 8-10 d (Fig. 1b,c). In each cell, two to four nucleoli were present. In the post-confluent culture (about the 14th day), mammary epithelial cells formed dome structures visualized by a bright-field microscope (Fig. 1d). Dome structures were also visualized under confocal microscopy and their diameters measured. These structures possessed an average diameter of $220 \mu \mathrm{m}( \pm 20 \mu \mathrm{m}$; Fig. 1e, f).

Primary epithelial cells were cloned by serial dilutions and homogeneity was obtained after the first passage. Epithelial cells in the second and third passages had normal morphology and grew faster. The state of confluency was obtained after the third or fourth day of culture, which was earlier than in the primary cell culture.

Immunochemistry of mammary epithelial cells. Cell cultures were identified by staining of the cytokeratin elements of the cytoskeleton. A strong signal for cytokeratins was detected in cells from primary cell cultures and the first to third passages. In primary cell cultures, some cells were found negative for cytokeratin staining, which confirmed the heterogeneity of this cell population at that stage and the presence of other non-epithelial cell types. Homogeneity was obtained in the first to third passages of mammary cell cultures. The results were visualized using two separate methods, i.e., DakoCytomation EnVision+ System-HRP (Fig. 2a, b) and FITC-labeled anti-mouse IgG antibody (Fig. $2 c, d$ ).

Mycoplasma testing. Cell cultures were fixed, stained with DAPI, and tested for the presence of Mycoplasma (Fig. 2e,f). All samples analyzed with a confocal laser microscope were microbiologically pure. The microscopic results were compared with PCR outcomes, which were also Mycoplasmanegative. Genomic DNA of $M$. bovis was used as a positive control in the amplification reaction.

Evaluation of the most stable reference genes for normalization. The primers for reference genes were highly specific as single peaks in the melting curve were observed after real-time PCR (data not shown). The data obtained during real-time PCR reactions were transformed to quantities and were analyzed using geNorm. Stability (M-gene stability measure) was analyzed. The pairwise variation $(V)$ between the normalization factor ( $\mathrm{NF}_{n}$, with $n$ genes as references) and the $\mathrm{NF}_{n+1}$ was calculated. The lowest pairwise variation $(V)$ appeared for three genes (V2/3). In many articles, a 0.15 value for $M$ (gene stability measure) is proposed, but as suggested by Vandesompele et al. (2002), the $M$ value can be modified. From the group of five chosen reference genes- $A C T B$, 
Figure 1. Bovine mammary epithelial cells. $a$ Primary cell culture (light microscopy; magnification, $\times 400$ ). $b$ Primary cell cultures stained with Giemsa solution (magnification, $\times 40$ ). $c$ Primary cell cultures stained with Giemsa solution (light microscopy; magnification, $\times 200)$. $d$ Dome structure of primary epithelial cell culture (light microscopy; magnification, $\times 400$ ). $e, f$ Dome structures stained with propidium iodide (confocal laser scanning microscopy; magnification, $\times 600$ ).
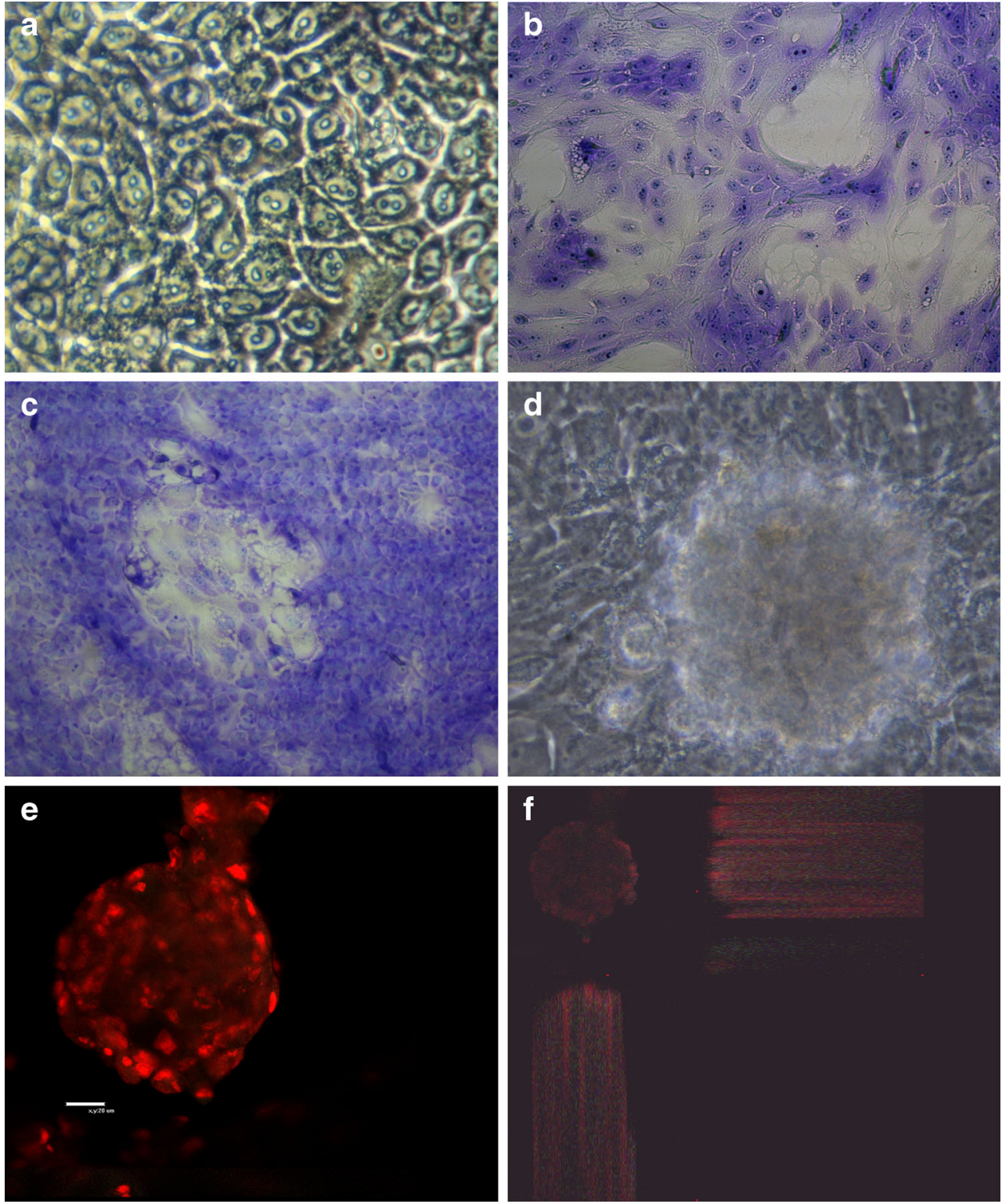

GAPDH, UXT, 18S rRNA, and 28S rRNA - the most stable genes were selected for mammary tissue fragments, epithelial cell cultures, and for the combination of the previous two groups. For mammary gland tissue samples, GAPDH and $U X T$ proved the most stable genes (best references, $\mathrm{NF}_{2}$ ). $A C T B$ was chosen for the normalization factor $\mathrm{NF}_{2+1}$ (addition of extra reference gene). For the GAPDH, UXT, and $A C T B$ genes, the $V$ value was equal to 0.367 . In cell cultures, the UXT, GAPDH, and ACTB genes served as the most suitable references. For three chosen genes, V2/3, $V$ was equal to 0.197 . In the combined group, GAPDH, UXT, and, in addition, $A C T B$ were selected. For the combined group, the $V$ value was the highest when compared with the two previous analyzed groups, but from the five studied gene variants the lowest $V$ value $(V=0.666)$ was obtained for the three genes.
Milk-specific gene expression. The primers for the experimental genes were also highly specific, and single peaks were observed in the melt curve after real-time PCR (data not shown). The reactions were designed to analyze the relative expression levels of casein genes (CSN1S1, CSN1S2, CSN2, $C S N 3$ ); whey protein genes ( $L A L B A$ and $B G L)$; and butyrophilin gene (BTN1A1) in tissue fragments (Fig. 3) and mammary cell cultures (Fig. 4). Analysis of the results confirmed the high level of expression of all the experimental genes in the tissue fragments obtained from lactating cows $(n=5)$. In four of five samples obtained from individuals in the involution phase, the expression of all analyzed genes was confirmed (Fig. 3). In one sample, lack of BTN1A1 gene expression was noticed. In the tissue fragments analyzed from heifers $(n=2)$, the CSN1S2 and CSN2 genes were expressed 
Figure 2. Bovine mammary epithelial cells. $a, b$ Domes of primary cell cultures immunostained against cytokeratins (light microscopy; magnification, $\times 100)$. $c$ Second passage immunostained against cytokeratins (confocal microscopy; magnification, $\times 400$ ). $d$ Third passage immunostained against cytokeratins and DAPI (confocal microscopy, $\times 400$ ). $e$ Primary cell culture stained with DAPI, free of microbiological contamination $(\times 400) . f$ Second passage stained with DAPI, free of microbiological contamination (confocal microscopy, $\times 600$ ).
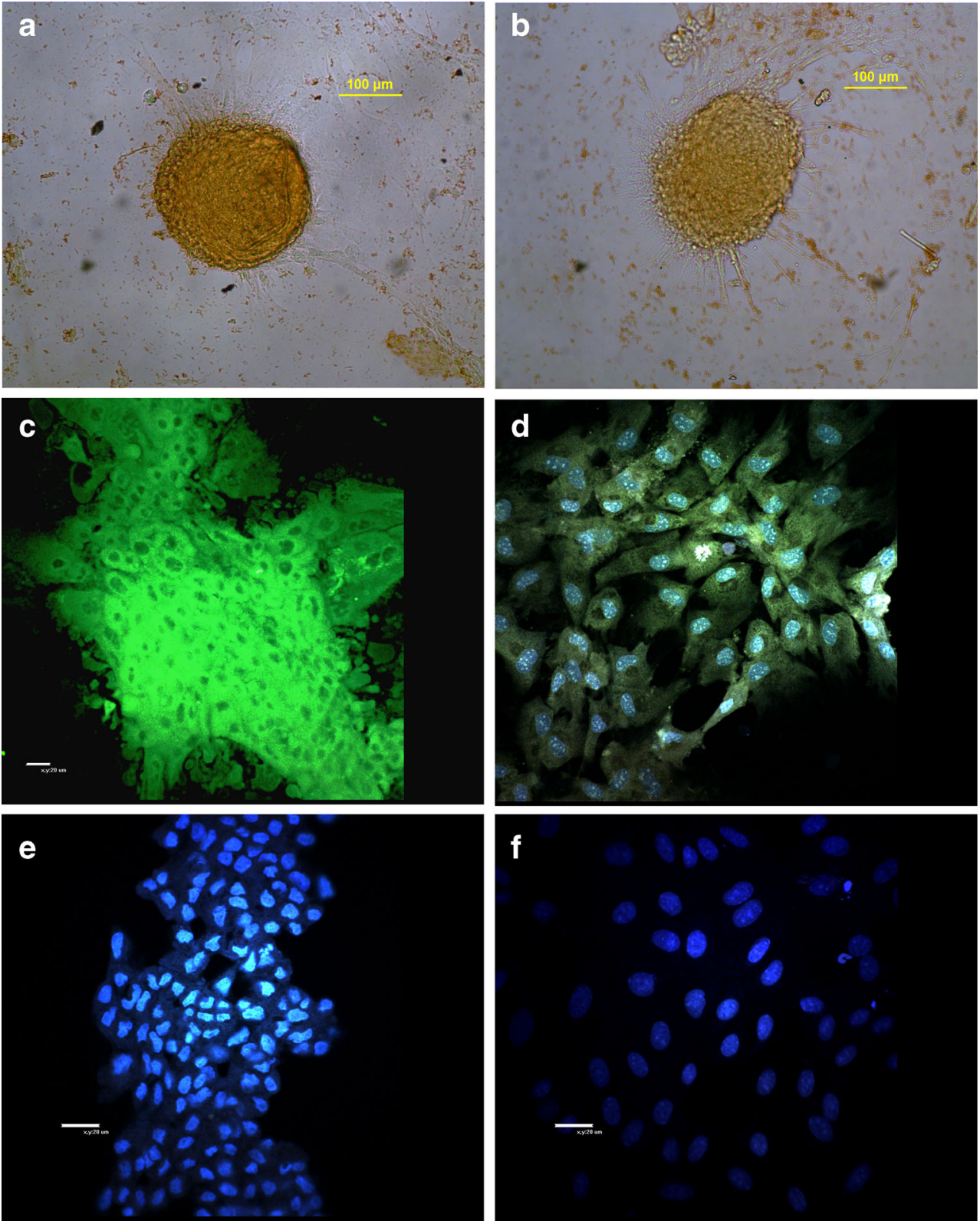

at very low levels in all the samples tested. In this group, the expression of CSN3, LALBA, BGL, and BTN1A1 was confirmed at a very low level in one sample. For heifer samples, lack of CSN1S1 gene expression was noticed. Differences of the relative expression levels of the studied genes in the three studied groups of samples (heifers, lactation, involution) were high, but not significant.

In the group of primary cell cultures, the expression of all casein genes, whey protein genes, and butyrophilin gene was detected. Primary cell cultures presented the highest relative expression levels of the CSN1S1, CSN2S2, CSN2, and CSN3 genes when compared with further passages (Fig. 4). For $\angle A L B A$, a low level of expression was observed in all maintained cultures. For the first passage, only the expression of
CSN1S2 and CSN2 genes was present. The expression of the CSN1S2 gene was relatively high. CNS2 gene expression was observed at a very low level in all analyzed cultures. No cells from the first passage were expressing whey protein genes or BTN1A1 gene. In contrast, cells in the second passage expressed all analyzed genes, with the highest level of expression of the $B G L$ gene. In the group from the third passage, lack of $L A L B A$ gene expression was noticed. Expression of the other analyzed genes was confirmed. The highest expression level of BTN1A1 was observed in the third passage.

Relative CSN1S1 gene expression was significantly higher $(\mathrm{P}<0.001)$ in the primary culture compared to cells from the second passage. Significant $(P \leq 0.05)$ difference in the relative expression level was also found for the CSN2 gene, 
Figure 3. Relative normalized expression levels (logarithmic scale, rescaled values) of the analyzed genes of tissue fragments in three groups of individuals (heifers, $n=2$; lactation, $n=5$; involution, $n=5$, mean). Bars represent standard deviation.

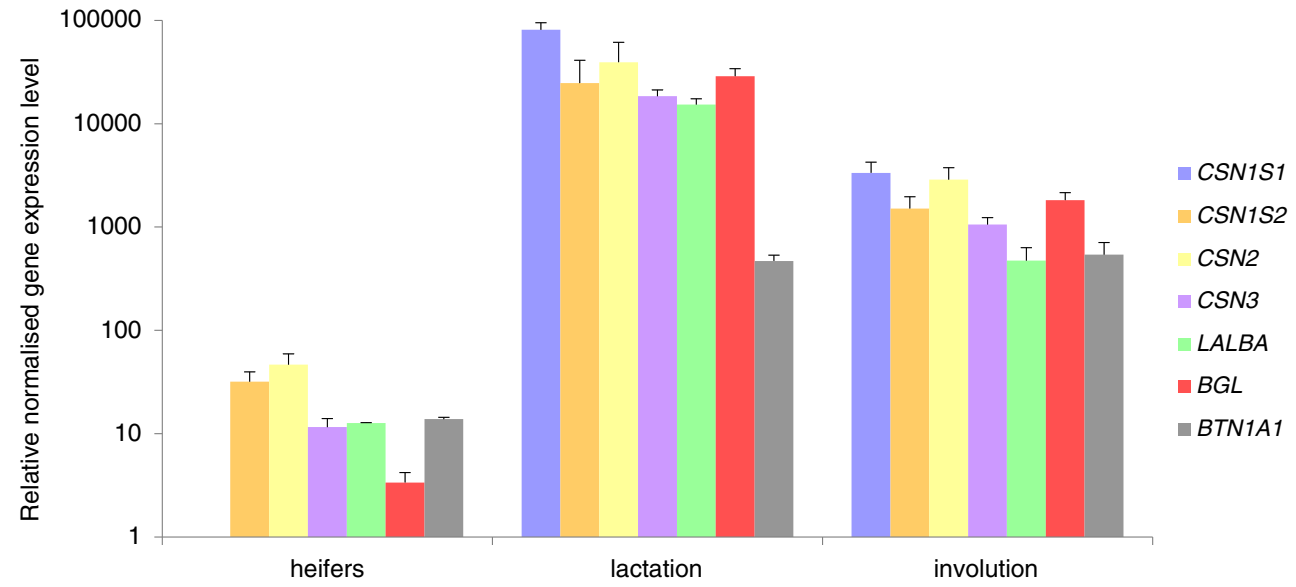

between the second and the third passages. Expression of the CSN3 gene differed significantly $(P \leq 0.01)$ between the primary culture and third passage cells. The only significant $(P \leq$ 0.01 ) difference in the relative expression level of whey protein genes was found for the $B G L$ gene between the primary culture and the second passage.

\section{Discussion}

The establishment and characterization of mammary epithelial cell (MEC) cultures of different species, e.g., bovine (Rose et al. 2002), buffalo (Anand et al. 2012), caprine (Ogorevc et al. 2009), ovine (Ilan et al. 1998), porcine (Sun et al. 2006), or rodents (Karantza-Wadsworth and White 2008), have been studied to identify a representative mammary epithelial cell model to better understand the phenomenon of mammary biology (Rose and McConochie 2006). Mammary epithelial cell cultures are an alternative attempt to the previously used explant cultures, which have been used as a model in studies on mammary gland function (Rose and McConochie 2006). Experiments on explants give a possibility to study mammary gland functions as they are the closest model resembling mammary tissue. They provide an opportunity to monitor the processes similar to those occurring in vivo, but one of the main drawbacks of this cellular model is that it remains viable for a limited period of time (Rose and McConochie 2006). Primary MEC cultures can also be utilized in studies on mammary gland physiology as a material that is related to the mammary gland tissue. On the other hand, this model is quite difficult to obtain, cells in primary cell culture must be cytologically indentified (cell population in this type of cultures is not homogeneous), and the experimental time with this material is also relatively short. An alternative approach is to use immortalized and clonal cell lines. These models are easy to maintain and, theoretically, cells in every passage are identical. The MAC-T cell line is the most popular immortalized MEC, but the results obtained in experiments with MAC-T proved that it was not a single homogeneous cell line (Zavizion et al. 1995a, b; Rose and McConochie 2006). Some observations showed that MAC-T had a very low production level of milk-specific proteins (German and Barash 2002; Rose and McConochie 2006). In addition, the study of Huynh et al. (1991) revealed that the growth of cells of this line is not dependent on some
Figure 4. Relative normalized expression levels (logarithmic scale, rescaled values) in mammary epithelial cell cultures present as mean values established from all three groups of individuals $(n=10)$ in different lactation cycles. $* P \leq 0.05$; $* * P \leq 0.01 ; * * * P \leq 0.001$. Bars represent standard deviation.

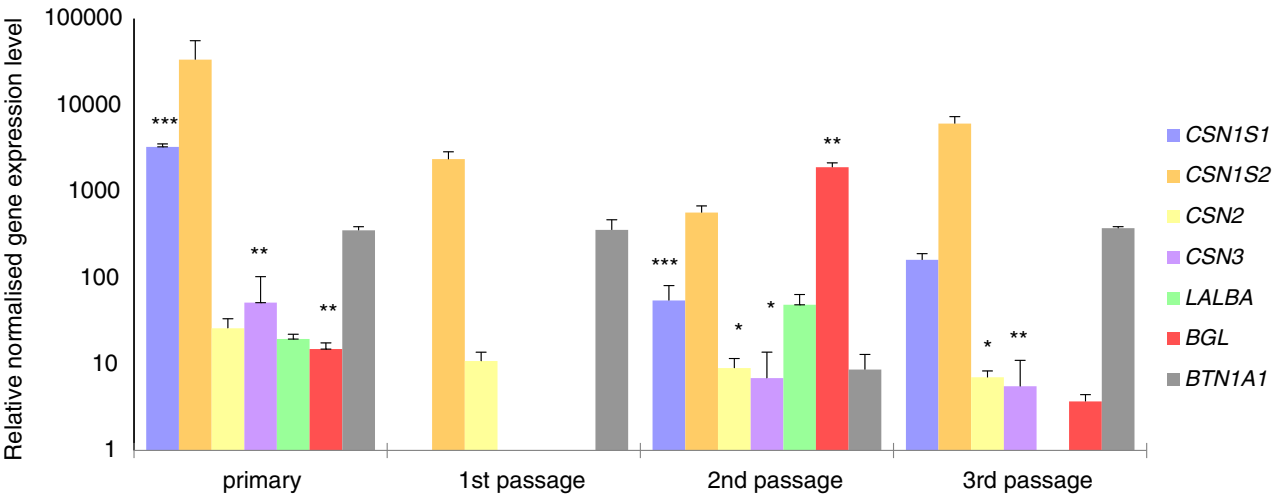


factors, e.g., hormones, growth factors, or extracellular matrix (Rose and McConochie 2006). Other bovine cell lines such as BMEC+H (Schmid et al. 1983), HH2A (Huynh and Pollak 1995), ET-C, and BME-UV (Zavizion et al. 1995a, b, 1996) were also tested, but it appeared that these lines had abnormalities not occurring in the normal, untransformed cultures (Matitashvili et al. 1997; Rose and McConochie 2006).

In this study, we have analyzed primary cell cultures and subsequent passages of the mammary gland tissue. What is more, we have also tested the mammary gland material for establishing cell cultures from three relevant bovine stages (non-lactating heifers, individuals in mid-lactation, and individuals in involution). Some studies present BMEC established from fragments of mammary parenchymal tissue obtained from pregnant individuals (Emerman et al. 1977; Huynh and Pollak 1995; Rose et al. 2002), but most often, the mammary cell cultures are established from lactating individuals (Pantschenko et al. 2000; German and Barash 2002; Hu et al. 2009; Zhao et al. 2010; Lu et al. 2012; Sorg et al. 2012). On the other hand, little is known about the suitability of tissue fragments from heifers in establishing primary cell cultures. Mammary epithelial cell cultures, especially organoids from heifer tissues, were analyzed in the past rather to examine the mitotic effects of cell proliferation (Berry et al. 2003; Thorn et al. 2008). In the current study, a very low level of CSN2 gene expression was detected in cultures obtained from all samples (heifers, lactation, and involution). Basic minimal culture medium and the fact that cells were maintained on a plastic surface could have affected the results. A low expression level of the casein genes was also confirmed in the tissue of non-lactating animals in the study by Suchyta et al. (2004). The mammary gland tissue fragments from heifers were the most effective materials for establishing primary cell cultures. Additionally, all tissue fragments from heifers gave rise to primary cell cultures, and all subsequent passages from the first to third were obtained. Furthermore, an expression of all casein and $B G L$ genes was at a very low level in primary cell cultures, while in first to third passages, only low expressions of $B G L$ (second passage), CSN1S2, and CSN2 (third passage) were observed.

Establishing primary MEC cultures from tissue obtained from individuals in involution was as effective as establishing primary mammary epithelial cell (PMEC) cultures from heifer tissue. The same results were obtained in the first and second passages. Some differences were noticed only in the third passage, where lower (seven of nine) numbers of passages were obtained. The relative expression level of the analyzed genes was low, while the expression of the LALBA gene was not observed. Few studies analyzed mammary cells from individuals in involution, and these studies were primarily focused on the process of involution. Generally, the most frequently used cellular models in experiments are still the transformed cell lines, e.g., BME-UV (Gajewska et al. 2005; Hernendez et al. 2009) or HC11 cell line (Kolek et al. 2003).

The most difficult part in our experiments was to establish primary MEC cultures from tissue collected from cows in lactation. Of 25 individuals, 19 PMEC cultures were established. In the first passage, 13 cultures were obtained, in the second 11, and in the third 10. It is possible that the difficulty in establishing and maintaining cell cultures from lactating individuals was associated with hormonal requirements. Many studies were performed in this area, but no uniform methods were applied. Culture media with different hormones and various concentrations were used in experiments of different studies. Generally, insulin, hydrocortisone, and prolactin are used most frequently (Huynh et al. 1991; Duo et al. 2006). However, in other experiments, the cell culture medium was supplemented with epidermal growth factor (EGF) or transferrin was used (German and Barash 2002; Hu et al. 2009). In the presented study, minimal culture medium was used, but in our other study (results not published), the effect of prolactin was noticed. Differences in the morphology of epithelial cell and gene expression were observed. Differences in the composition of the culture medium may influence the results not only in establishing and maintaining these cultures but also in the gene expression. Zhao et al. (2010) confirmed the presence of $\alpha$ s1 casein in primary cell cultures maintained on plastic dishes in medium containing insulin, hydrocortisone, prolactin, and EGF. Rose et al. (2002) also observed the expression of $\alpha$-casein in mammary epithelial cell cultures in passages 20,25, and 30, where cells were cultured on plates coated with collagen. Furthermore, the presence of $\alpha \mathrm{s} 1$ casein and $\mathrm{K}$-casein in two cell lines, MECHH and MEC-LL, was also noticed and analyzed when the cell culture were maintained on plastic substrate in a medium supplemented only with EGF (Lu et al. 2012). In the experiment with buffalo MEC culture on plastic substratum and collagen type I matrix, the expressions of CSN2, CSN3, $B T N 1 A 1$, and $L T F$ genes were determined using a RT-PCR method (Anand et al. 2012). In a bovine cell culture study, CSN2 and BTN1A1 gene expression was detected in BMEC cultures seeded on a plastic surface using RT$\mathrm{PCR}$, and the presence of CSN2 protein was confirmed by Western blotting ( $\mathrm{Hu}$ et al. 2009). In contrast, the expression of whey proteins was not frequently analyzed. $\alpha$-Lactalbumin expression was reported in caprine mammary epithelial cell line (Pantschenko et al. 2000; Bionaz and Loor 2007), whereas bovine L-1 and H-7 clonal mammary epithelial cell lines expressed BGL protein (German and Barash 2002). Although different patterns of milk-specific gene expressions were observed, many factors influencing the expression changes are unclear. Future studies will be focused on the comparison of a mammary cell culture model maintained in different culture conditions. 


\section{Conclusion}

On the basis of the presented experiments, we can conclude that the primary cultures and cells of the second passage appeared to be the most suitable materials for studying mammary gland function and gene expression activity. The results obtained in the present study provide new methodological information that can be used in future studies of mammary gland function.

Acknowledgments The authors are grateful to Dr. Dariusz Bednarek from the National Veterinary Research Institute in Pulawy (Poland) for providing genomic DNA of $M$. bovis.

Open Access This article is distributed under the terms of the Creative Commons Attribution License which permits any use, distribution, and reproduction in any medium, provided the original author(s) and the source are credited.

\section{References}

Anand V.; Dogra N.; Singh S.; Kumar S. N.; Jena M. K.; Malakar D.; Dang A. K.; Mishra B. P.; Mukhopadhyay T. K.; Kaushik J. K.; Mohanty A. K. Establishment and characterization of a buffalo (Bubalus bubalis) mammary epithelial cell line. PLoS ONE 7(7): $1-14 ; 2012$.

Berry S. D. K.; Weber Nielsen M. S.; Sejresn K.; Pearson R. E.; Boyle P. L.; Akers R. M. Use of an immortalized bovine mammary epithelial cell line (MAC-T) to measure the mitogenic activity of extracts from heifer mammary tissue: effects of nutrition and ovariectomy. Domest. Anim. Endocrinol. 25(3): 245-253; 2003.

Bionaz M.; Loor J. J. Identification of reference genes for quantitative real-time PCR in the bovine mammary gland during the lactation cycle. Physiol. Genomics 29(3): 312-319; 2007.

Buhering G.; Eby E.; Eby M. Cell line cross-contamination: how aware are mammalian cell culturists of the problem and how to monitor it? In Vitro Cell. Dev. Biol. Anim. 40(7): 211-215; 2004.

Chomczynski P.; Sacchi N. Single-step method of RNA isolation by acid guanidinium thiocyanate-phenol-chloroform extraction. Anal. Biochem. 162(1): 156-159; 1987.

Duo S.; Wu Y.; Luo F.; Bou S. Isolation, culture and biological characteristics of bovine mammary epithelial cells. Zool. Res. 27(3): 299 $305 ; 2006$.

Emerman J. T.; Enami J.; Pitelka D. R.; Nandi S. Hormonal effects on intracellular and secreted casein in cultures of mouse mammary epithelial cells on floating collagen membranes. Proc. Natl. Acad. Sci. U. S. A. 74(10): 4466-4470; 1977.

Gajewska M.; Gajkowska B.; Motyl T. Apoptosis and autophagy induced by TGF-B1 in bovine mammary epithelial BME-UV1 cells. $J$. Physiol. Pharmacol. 56(3): 143-157; 2005.

German T.; Barash I. Characterization of an epithelial cell line from bovine mammary gland. In Vitro Cell. Dev. Biol. Anim. 38(5): 282-292; 2002.

Hernendez L. L.; Limesand S. W.; Collier J. L.; Horseman N. D.; Collier R. $\mathrm{J}$. The bovine mammary gland expresses multiple functional isoforms of serotonin receptors. J. Endocrinol. 203(1): 123-131; 2009.

Hu H.; Wang J.; Bu D.; Wei H.; Zhou L.; Li F.; Loor J. L. In vitro culture and characterization of a mammary epithelial cell line from Chinese Holstein dairy cow. PLoS ONE 4(11): 1-8; 2009.

Huynh H. T.; Pollak M. HH2A, an immortalized bovine mammary epithelial cell line, expressed the gene encoding mammary derived growth inhibitor (MDGI). In Vitro Cell. Dev. Biol. Anim. 31(1): 25-29; 1995.

Huynh H. T.; Robitaille G.; Turner J. D. Establishment of bovine mammary epithelial cells (MAC-T): an in vitro model for bovine lactation. Exp. Cell Res. 197(2): 191-199; 1991.

Ilan N.; Barash I.; Gootwine E.; Shani M. Establishment and initial characterization of the ovine mammary epithelial cell line NISH. In Vitro Cell. Dev. Biol. Anim. 34(4): 326-332; 1998.

Jedrzejczak M. A bovine mammary epithelial cell culture an alternative model for study of modification and mammary gland functions. $\mathrm{PhD}$ dissertation, West Pomeranian University of Technology, Szczecin; 2010a.

Jedrzejczak M. Epithelial cell cultures in vitro-model for the study of mammary gland functions. In: Voivodship Labor Office in Szczecin (eds) Investment in knowledge, Szczecin 2:61-67; 2010 b.

Karantza-Wadsworth V.; White E. A mouse mammary epithelial cell model to identify molecular mechanisms regulating breast cancer progression. Methods Enzymol. 2(446): 61-76; 2008.

Kolek O.; Gajkowska B.; Godlewski M. M.; Motyl T. Co-localization of apoptosis-regulating proteins in mouse mammary epithelial $\mathrm{HC} 11$ cells exposed to TGF- $\beta_{1}$. Eur. J. Cell Biol. 82(6): 303-312; 2003.

Kong F.; James G.; Gordon S.; Zelynski A.; Gilbert G. L. Species-specific PCR for identification of common contaminant mollicutes in cell culture. Appl. Environ. Microbiol. 67(7): 3195-3200; 2001.

Kozłowski M.; Motyl T. Use of three-dimensional cultures (3D) in the investigation of bovine mammary gland biology. Med. Weter. 63(Supp 11): 1417-1420; 2007.

Kuppeveld F. J. M.; Johansson K. E.; Galama J. M. D.; Kissing J.; Bölske G.; van Der Logt J. T. M.; Melchers W. J. G. Detection of Mycoplasma contamination in cell cultures by a mycoplasma groupspecific PCR. Appl. Environ. Microbiol. 60(1): 149-152; 1994.

Loor J. J.; Cohick W. S. ASAS Centennial Paper: Lactation biology for the twenty-first century. J. Anim. Sci. 87(2): 813-824; 2009.

Lu C.; Yang R.; Liu B.; Li Z.; Shen B.; Yan S.; Zhang Y.; Zhang L.; Zhao Z. Establishment of two types of mammary epithelial cell lines from Chinese Holstein dairy cow. J. Anim. Vet. Adv. 11(8): 1166-1172; 2012.

Matitashvili E.; Bramley A. J.; Zavizion B. An in vitro approach to ruminant mammary gland biology. Biotechnol. Adv. 15(1): 17-41; 1997.

Moll R.; Franke W. W.; Schiller D. The catalog of human cytokeratins: patterns of expression in normal epithelia, tumors and cultured cells. Cell 31(1): 11-24; 1982.

Ogorevc J.; Prpar S.; Dovč P. In vitro mammary gland model: establishment and characterization of a caprine mammary epithelial cell line. Acta Agric. Slov. 94(2): 133-138; 2009.

Pantschenko A. G.; Woodcock-Mitchell J.; Bushmich S. L.; Yang T. J. Establishment and characterization of a caprine mammary epithelial cell line (CMEC). In Vitro Cell. Dev. Biol. Anim. 36(1): 26-37; 2000.

Povey R. C.; Osborne A. D. Mammary gland neoplasia in the cow: a review of literature and report of a fibrosarcoma. Pathol. Vet. 6(6): 502-512; 1969.

Rose M. T.; McConochie $\mathrm{H}$. The long road to a representative in vitro model of bovine lactation. JIFS 3(3): 67-72; 2006.

Rose M. T.; Aso H.; Yonekura S.; Komatsu T.; Hagino A.; Ozutsumi K.; Obara Y. In vitro differentiation of a cloned bovine mammary epithelial cell. J. Dairy Res. 69(3): 345-355; 2002.

Ryan J. A. Single cell cloning by serial dilution. Corning Incorporated Live Science, 1-3; 2005.

Schmid E.; Schiller D. L.; Grund C.; Stadler J.; Franke W. W. Tissue typespecific expression of intermediate filament proteins in a cultured epithelial cell line from bovine mammary gland. J. Cell Biol. 96(1): 37-50; 1983

Sorg D.; Potzel A.; Beck M.; Meyer H. H. D.; Viturro E.; Kliem H. Effect of cell culture techniques on gene expression and cholesterol efflux in primary bovine mammary epithelial cells derived from milk and tissue. In Vitro Cell. Dev. Biol. Anim. 48(9): 550-553; 2012. 
Suchyta S. P.; Sipkovsky S.; Halgren R. G.; Kruska R.; Elftman M.; Weber-Nielsen M.; Vandehaar M. J.; Xiao L.; Tempelman R. J.; Coussens P. M. Bovine mammary gene expression profiling using a cDNA microarray enhanced for mammary-specific transcripts. Physiol. Genomics 16(1): 8-18; 2004.

Sun Y. L.; Lin S. C.; Chou Y. C. Establishment and characterization of a spontaneously immortalized porcine mammary epithelial cell line. Cell Biol. Int. 30(12): 970-976; 2006.

Thorn S. R.; Purup S.; Vestefgaard M.; Sejrsen K.; Meyer M. J.; Van Amburgh M. E.; Boisclair Y. R. Regulation of mammary parenchymal growth by the fat pad in prepubertal dairy heifers: role of inflammation-related proteins. J. Endocrinol. 196(3): 539-546; 2008.

Vandesompele J.; De Preter K.; Pattyn F.; Poppe B.; van Roy N.; De Paepe A.; Speleman F. Accurate normalization of real-time quantitative RT-PCR data by geometric averaging of multiple internal control genes. Genome Biol. 3(7): 0034.1-0034.11; 2002.
Wirth M.; Berthold E.; Grashoff M.; Pfützner H.; Schubert U.; Hauser H. Detection of mycoplasma contaminations by the polymerase chain reaction. Cytotechnology 16(2): 67-77; 1994.

Zavizion B.; Gorewit R. C.; Politis I. Subcloning the MAC-T bovine mammary epithelial cell line: morphology, growth properties, and cytogenetic analysis of clonal cells. J. Dairy Sci. 78(3): 515-527; 1995a.

Zavizion B.; van Duffelen M.; Schaeffer W.; Politis I. Use of microinjection to generate an immortalized bovine mammary cell line with both epithelial and myoepithelial characteristics. Method Cell Sci. 17(4): 271-282; 1995 b.

Zavizion B.; van Duffelen M.; Schaeffer W.; Politis I. Establishment and characterization of a bovine mammary epithelial cell line with unique properties. In Vitro Cell. Dev. Biol. Anim. 32(3): 138-148; 1996.

Zhao K.; Liu H. Y.; Zhou M. M.; Liu J. X. Establishment and characterization of a lactating bovine mammary epithelial cell model for the study of milk synthesis. Cell Biol. Int. 34(7): 717-721; 2010. 